\title{
Wireless Sensor Network Based Weather Forecasting
}

\author{
${ }^{1}$ Suleiman Audu Tarfa, ${ }^{2}$ Chukwuemeka Chijioke Nwaobasi \\ ${ }^{1,2}$ Dept. of Electrical and Electronics, Engineering Technology, Federal Polytechnic, Mubi, Adamawa State, Nigeria
}

\begin{abstract}
Weather forecasting is a complex and challenging science that depends on the efficient interplay of weather observation, data analysis by meteorologist and computers, and rapid communication system. Monitoring, controlling, and gathering environmental/weather conditions or parameters can easily be achieved with the use of wireless sensor networks. This system was built around Arduino Nano Microcontroller. This research simulated and implemented a modern method of collecting and storing environmental data; this method was used because of its accuracy, versatility, and speed. The result shows these parameters: humidity, temperature, atmospheric pressure and wind speed plotted in GUI graph in real time form.
\end{abstract}

Keywords: Wireless Sensor Networks, Interfacing, Microcontroller, Sensor, Weather, Software.

\section{INTRODUCTION}

In present era weather prediction and analysis has become a challenging problem around the world, reason behind are the two main factors: Firstly, it is useful for many human activities like agriculture sector, tourism and natural disaster prevention. Secondly, due to various technological advances like the growth of computational power and ongoing improvements in measuring systems[1]. In weather prediction the first step in predicting is collecting data. This is because one needs to know the weather history in the area which is the key principles of weather forecasting that past patterns can indicate future events. The process of collecting the data is referred to as data logging (data logger is a portable measurement device that is capable of autonomously recording environmental weather variables over a given time and stored at regular intervals). Thankfully, people no longer need to do this all by themselves, satellites in space collects data, and weather stations all over the worlds but having the implication of cost and maintenance in mind. Once the historical data are collected, the next step is to use various data mining techniques for analysis like prediction [2]. The collection of environmental variables such as temperature, pressure and humidity has a long history of development and the variables have shown significant impact in the productivity of plant growth, the quality of food industry and the efficiency of many temperature and humidity-sensitive equipment [3]. The monitoring of temperature and humidity of laboratories, storages, food processing, halls, school and hospitals is important with respect to health and hygiene [4]. Sudan has a rich weather information records, however collection of weather data from stations is not automatic but is done by telephone. Arduino, the open source hardware has shown ability to meet the need of accurate and real-time monitoring and controlling of environmental variables. Arduino is use in a wide range of projects to develop objects that can interact with people or environment and internet [5].

\subsection{Sensor Classification}

The sensors chosen for an application depend on the physical property and range to be monitored, for example, such properties include wind, temperature, pressure, light, or humidity [6].Table 1 below summarizes some common physical properties, including examples of sensing technologies that are used to capture them

Table 1: Classification and examples of some sensors [7]

\begin{tabular}{|c|c|}
\hline Types & A4 \\
\hline Temperature & $\begin{array}{c}\text { Thermistors, } \\
\text { thermocouples, DHT11, } \\
\text { LM35, RTDs }\end{array}$ \\
\hline Pressure & $\begin{array}{l}\text { Pressure gauges, } \\
\text { barometers, ionization } \\
\text { gauges, BMP180 }\end{array}$ \\
\hline Optical & $\begin{array}{c}\text { Photodiodes, } \\
\text { phototransistors, infrared } \\
\text { sensors, CCD sensors }\end{array}$ \\
\hline Acoustic & $\begin{array}{c}\text { Piezoelectric resonators, } \\
\text { microphones }\end{array}$ \\
\hline Electromagnetic & $\begin{array}{c}\text { Hall-effect sensors, } \\
\text { magnetometers }\end{array}$ \\
\hline vibration & $\begin{array}{c}\text { Accelerometers, } \\
\text { gyroscopes, photo } \\
\text { sensors Capital letter }\end{array}$ \\
\hline Wind flow & 10 point, Bold \\
\hline Position & $\begin{array}{l}\text { GPS, ultrasound-based } \\
\text { sensors, infrared-based } \\
\text { sensors, inclinometers }\end{array}$ \\
\hline Radiation & $\begin{array}{c}\text { Ionization detectors, } \\
\text { Geiger-Mueller counters }\end{array}$ \\
\hline
\end{tabular}

Besides physical properties, the classification of sensors can be based on a variety of other methods, for example, 
whether they require an external power supply [8]. If the sensors require external power, they are referred to as active sensors. (e.g., microwaves, light, sound) to trigger a response or to detect a change in the energy of the transmitted signal. The performance of sensor is characterized by: Transfer function, sensitivity, range, accuracy/uncertainty, hysteresis, and linearity, Noise, resolution and bandwidth.

\section{SYSTEM DESCRIPTION}

The materials needed for the completion of this project are listed in table 1 below

Table: 2: Materials required for the design

\begin{tabular}{|c|c|}
\hline Component & Description \\
\hline $\begin{array}{l}\text { Xbee Series } 2 \text { radio } \\
\text { Module }(\mathrm{s} 2 \mathrm{c})\end{array}$ & $\begin{array}{c}\text { A pair of xbee modules } \\
\text { for wireless } \\
\text { communication }\end{array}$ \\
\hline $\begin{array}{l}\text { Arduino Nano } \\
\text { Microcontroller }\end{array}$ & $\begin{array}{l}\text { Microcontroller for both } \\
\text { the receiving and } \\
\text { transmitting end of this } \\
\text { work }\end{array}$ \\
\hline Bmp 180 Barometer Sensor & $\begin{array}{c}\text { For measuring } \\
\text { atmospheric pressure }\end{array}$ \\
\hline $\begin{array}{c}\text { DHT } 11 \text { Temperature and } \\
\text { Humidity Sensor }\end{array}$ & $\begin{array}{c}\text { For measuring humidity } \\
\text { and temperature }\end{array}$ \\
\hline Windspeed Sensor & $\begin{array}{l}\text { For measuring wind } \\
\text { speed and direction }\end{array}$ \\
\hline Proteus 8.0 professional & $\begin{array}{l}\text { Software used for } \\
\text { simulation }\end{array}$ \\
\hline MATLAB & $\begin{array}{c}\text { Software used to design } \\
\text { GUI }\end{array}$ \\
\hline $\begin{array}{c}\text { Arduino Integrated } \\
\text { Development Environment } \\
\text { (IDE) }\end{array}$ & $\begin{array}{l}\text { Software Used to write } \\
\text { microcontroller } \\
\text { instructions }\end{array}$ \\
\hline $\begin{array}{l}\text { Virtual Serial Port Emulator } \\
\text { (VSPE) }\end{array}$ & $\begin{array}{l}\text { Software used to } \\
\text { simulate wireless } \\
\text { communication }\end{array}$ \\
\hline
\end{tabular}

The method used in actualizing this project is summarized in the block diagram of figure 1 . The block diagram shows how stages of the project or components are interphase with each other to form the complete unit.

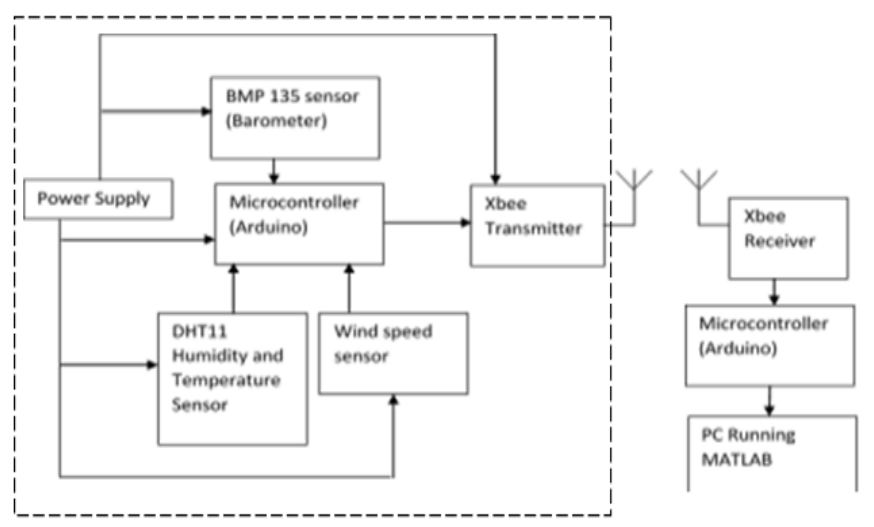

Figure 1: Block diagram of the design

\subsection{Design procedure}

The implementation of this research work was carried out in two major phases; - Hardware and

Software The hardware aspect involves the design of the various units making up the system; this is followed immediately by the implementation of each block. The software algorithm was developed using assembling language

\subsection{Power supply}

The Power supply used in the transmitter part of this project is $9 \mathrm{~V}$ alkaline battery. Apart from the availability and low cost of this battery, it was also preferred due to the fact that the arduino microcontroller has an onboard $5 \mathrm{~V}$ voltage regulator. The $9 \mathrm{~V}$ alkaline battery is connected, through a battery connector, to the "VIN" pin of the arduino nano microcontroller, $5 \mathrm{~V}$ is then tapped off the $5 \mathrm{~V}$ pin of the controller. Figure 2 is the picture of a $9 \mathrm{~V}$ alkaline battery and the battery connector.
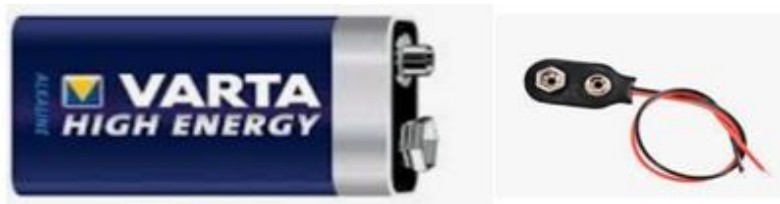

Figure 2: 9V Alkaline Battery and Battery Connector

\subsection{BMP 180 Barometer Sensor}

The BMP180 is low power consumption and accurate sensor that can be used to measure atmospheric pressure as the pressure varies with changes in weather. The sensor is made up of piezo resistive semiconducting material. Changes in resistance occur when atmospheric pressure is applied to the sensor. The sensor can be directly interfaced to a controller using the i2c communication protocol. Figure 3 is a picture of the sensor.

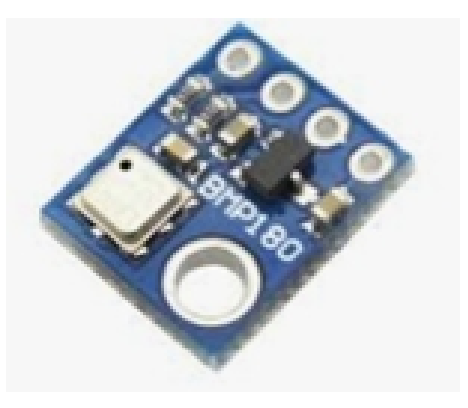

Figure 3: BMP 180 Sensor

\subsection{DHTII Temperature and humidity sensor}

The DHTII is a temperature and humidity sensor. It uses capacitive humidity sensor and a thermistor to measure the 
surrounding air and dishes out digital signal on its data pin which will be read by the controller if careful hardware and software interfacing is done. Software interfacing involves writing codes to read temperature and humidity data from the sensor. The codes are displayed at the appendix section of this work. Figure 4 is a picture of the sensor.

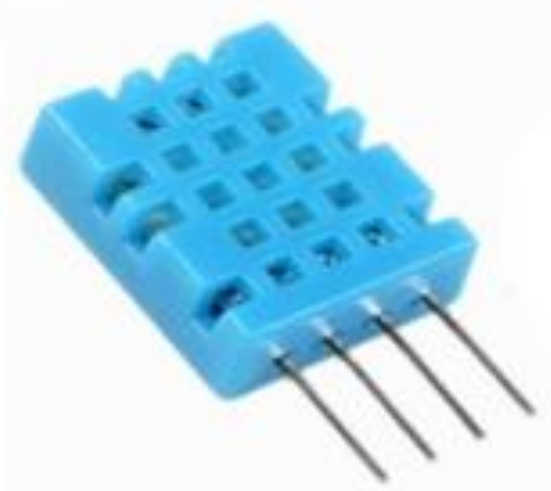

Figure 4: DHTII Sensor

\subsection{Xbee S2C Radios}

XBee $\mathrm{S} 2 \mathrm{C}$ is a RF module designed for wireless communication or data exchange and it works on ZigBee mesh communication protocols that sit on top of IEEE 802.15.4 PHY. The module provides wireless connectivity to end-point devices in any ZigBee mesh networks including devices from other vendors. With a few of these modules the user can setup their own ZigBee network up-and-running in a matter of minutes. The XBee RF Module is compatible with other units that use ZigBee technology. These include other XBee modules, Connect Ports gateways, XBee and XBeePRO Adapters, XBee Sensors and other products that are designated with "ZB" product name. Figure 5 is a picture of the XBEE S2C module and its adapter.
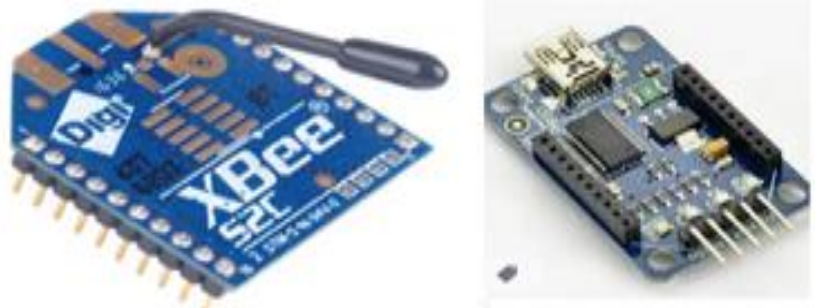

Figure 5: XBEE S2C and XBEE USB adapter

For configuring the module the user has to use X-CTU software developed by Digi International. Figure 6 is a picture of the XCTU software interface. To connect the XBee to the software, the xbee is inserted into the adapter and the adapter connected to the USB port of a computer using a mini B USB cable.

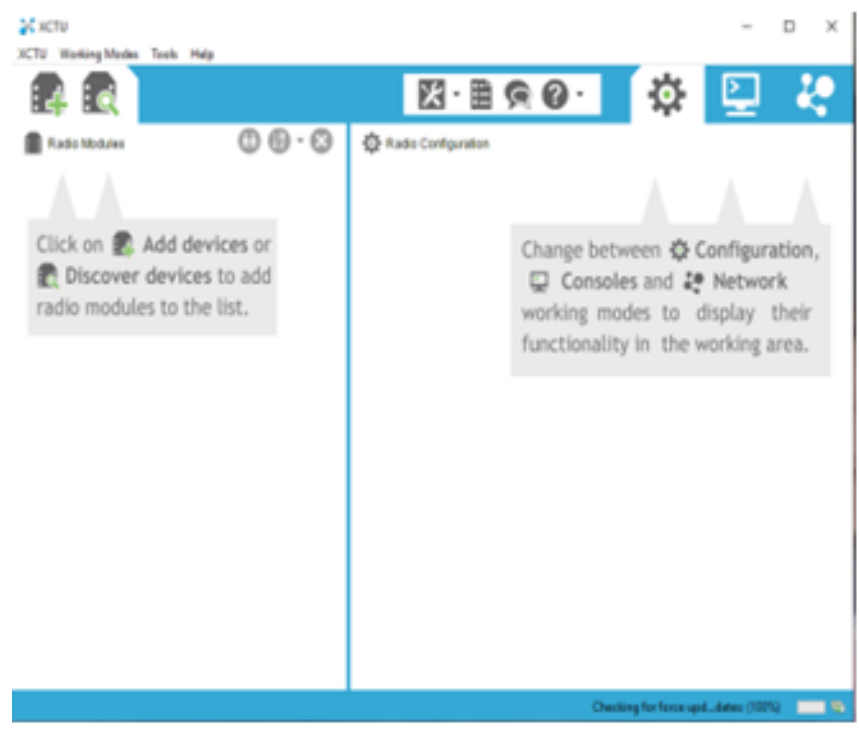

Figure 6: XCTU software interface

\subsection{Wind Speed Sensor (Anemometer)}

Anemometer is an instrument used to measure wind speed. This work is aimed at collecting weather data from the environment or atmosphere. Wind speed is part of this data needed and so in this work, an anemometer was constructed from the most basic and available parts. This anemometer was constructed from a dc motor, a table tennis ball, bearings harvested from an old hard disk, and also acrylic material for the casing. The bearing from the hard disc make it easy for the device to rotate at the slightest of winds. The picture of the constructed anemometer is shown in figure 7 below.

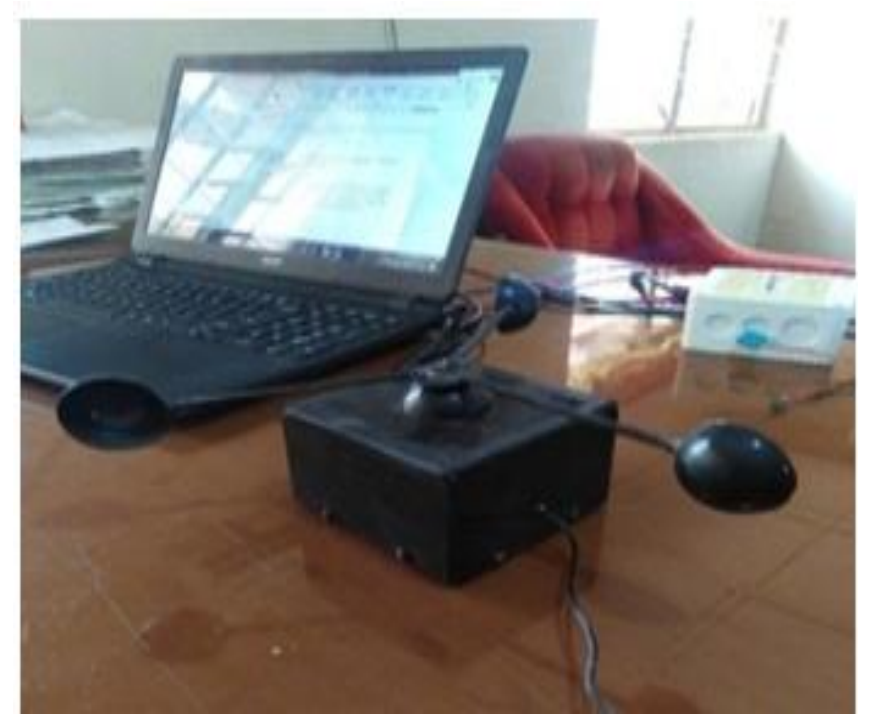

Figure 7: Constructed anemometer used to measure wind speed

To calibrate the device, an AM-4812 anemometer was placed side by side with the constructed anemometer and readings from both devices taken. Figure 8 is a picture of the AM-4812 anemometer. 
ISSN (online): 2581-3048

IRJIET

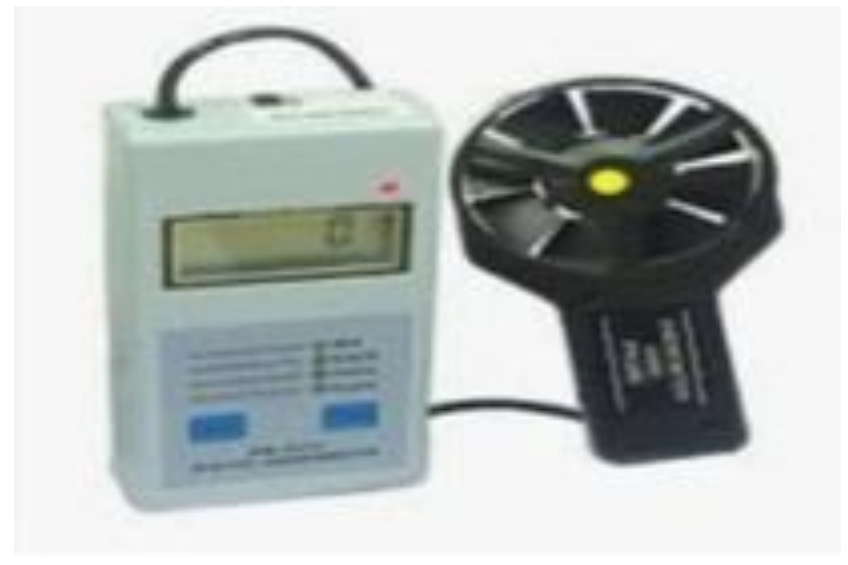

Figure 8: AM-4812 anemometer

Readings from the constructed anemometer were taking using a multimeter, while readings from the AM-4812 anemometer were taken directly from its display. After collecting this data, a relationship was established between both devices by plotting a line of best fit between them. The relationship or equation of the line of best fit is then programmed into MATLAB such that whenever readings from the constructed anemometer comes in, MATLAB converts this reading to wind speed in $\mathrm{kmh}-1$ using the above formula and plots and data logs the data. Codes used for this regression line can be found at the appendix of this work.

\subsection{PC Running MATLAB}

In this work, data collected from sensors were logged into a computer. The data collected were logged through a graphics user interface (GUI) written in MATLAB. The GUI possesses a dash board containing plots of all the data being logged in real time. The GUI also has buttons which when clicked executes various functions.. To log data, the GUI is invoked and the receiving part of this work is connected to the computer. The communications port is then entered into the text box of the GUI and the connect button clicked, communication is immediately established and data begins to stream in in real time. Also graphs of all four data are plotted in real time.

\subsection{Simulation Softwares}

Simulation was done using the following softwares: Arduino Integrated Development Environment (IDE). The arduino software was used to write codes for the controller in both the transmitter and receiver sections. This is because after compiling the codes, the hex file was sent to proteus for simulation purpose. It will be adequate to state that the same code used for the simulation is the same code used to program the real controllers, see figure 9 .
Volume 5, Issue 9, pp 14-20, September-2021 https://doi.org/10.47001/IRJIET/2021.509003

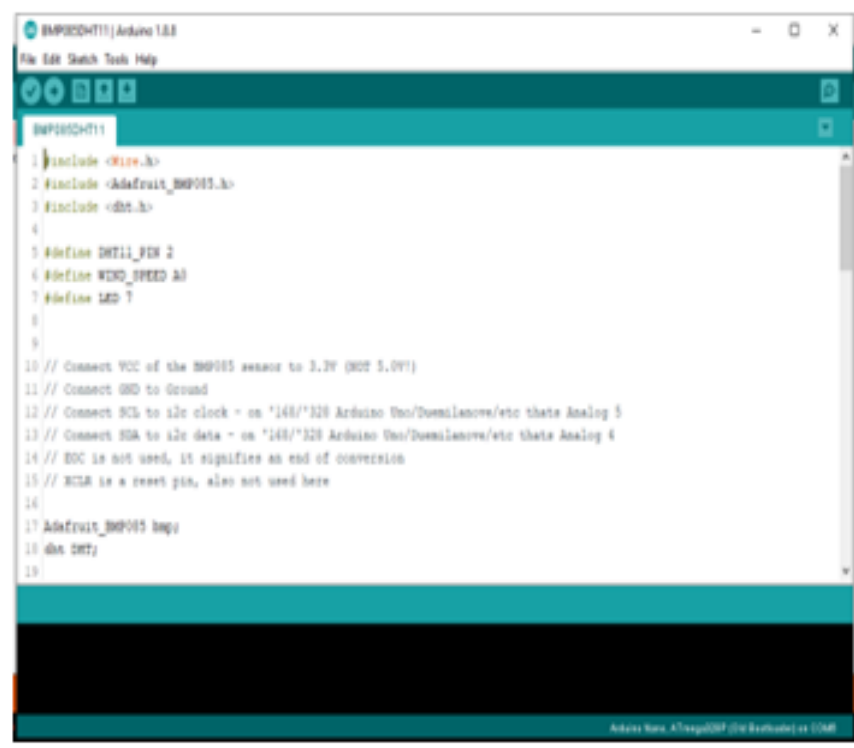

Figure 9: Arduino IDE and codes used

\section{Virtual Serial Port Emulator}

(VSPE) was used in other to simulate the wireless section of the codes VSPE was employed. Without this software it will be impossible to push data from proteus to MATLAB in the simulation for graph plotting. Figure 10 shows the GUI of VSPE.

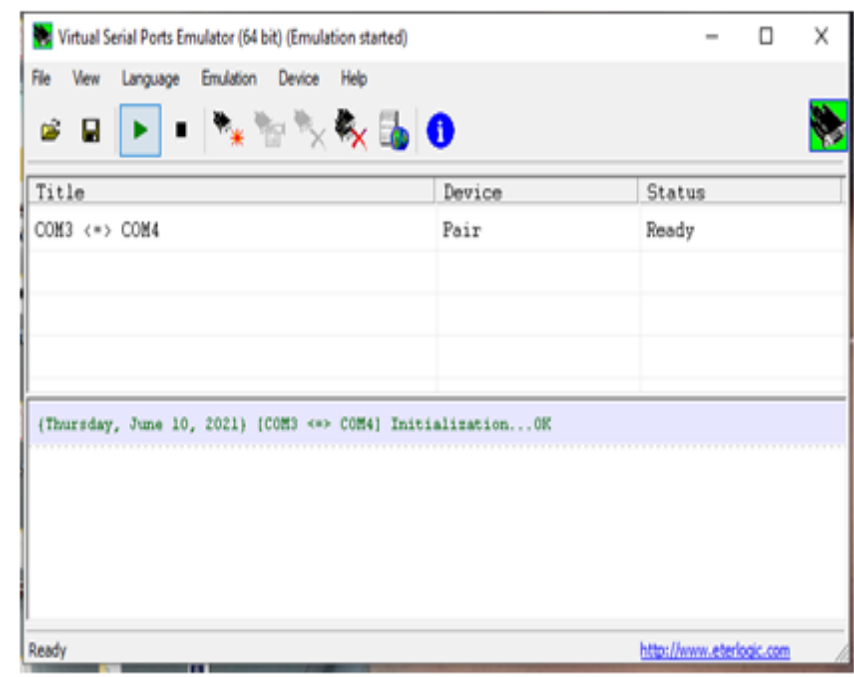

Figure 10: VSPE IDE

Proteus 8.0 Professional software was used to not only draw the circuit diagram for the entire system but also to simulate. To start the simulation, all blocks that form the circuit diagram were invoked and connected. The microcontroller, which is an arduino nano, was also invoked and the path of the hex file from the arduino IDE was copied into the arduino nano block of proteus and then the run simulation button was clicked. Figure 11 is the simulation of this work. 


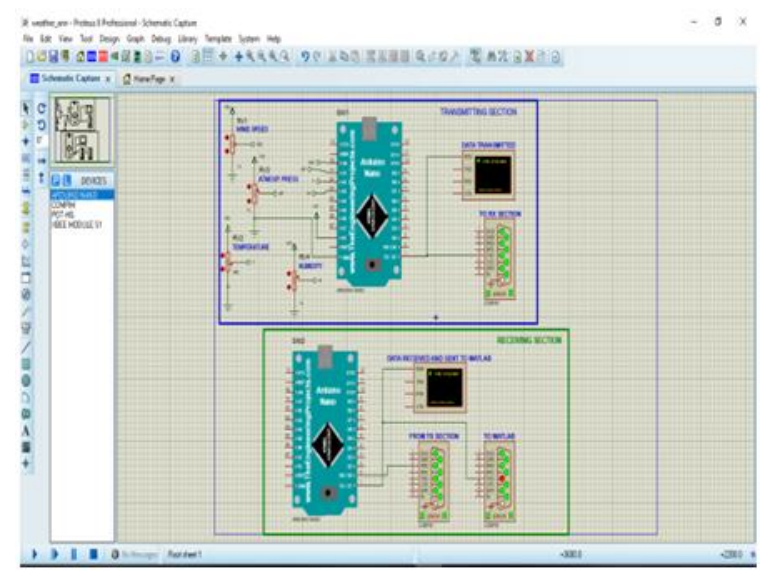

Figure 11: Simulation using Proteus

The four sensors used to collect data were simulated using a potentiometer (POT). This is because the real life data are available in the analog form and so varying them (to simulate changes in weather) will be easier using POTs. Secondly, blocks for the barometer, humidity and wind speed sensors are not available in proteus. Also, wireless communication between controllers and between controller and MATLAB was achieved using the COMPIN block of proteus. A virtual port was first created using VSPE and this port pairs were then entered into the COMPIN block. This is how the xbee modules were simulated. A virtual terminal was attached to each of the COMPIN blocks so that when the simulation is running, data flow can be visualized for debugging purposes.

MATLAB R2015a. This software was used to write the GUI in which the whole system of this works (see figure 13). After configuring the communications port (coms port) from the VSPE, the appropriate com port is entered into the GUI, and as soon as communication is established, data begins to log in and graphs are plotted in real time. The complete circuit diagram of the system is shown on figure 12 and figure 13 respectively.

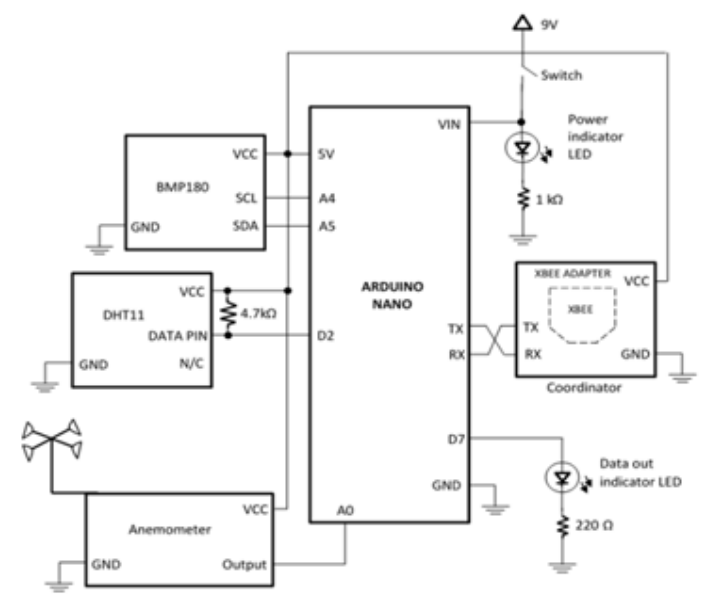

Figure 12: Circuit Diagram of Transmitter Section
ISSN (online): 2581-3048

Volume 5, Issue 9, pp 14-20, September-2021 https://doi.org/10.47001/IRJIET/2021.509003

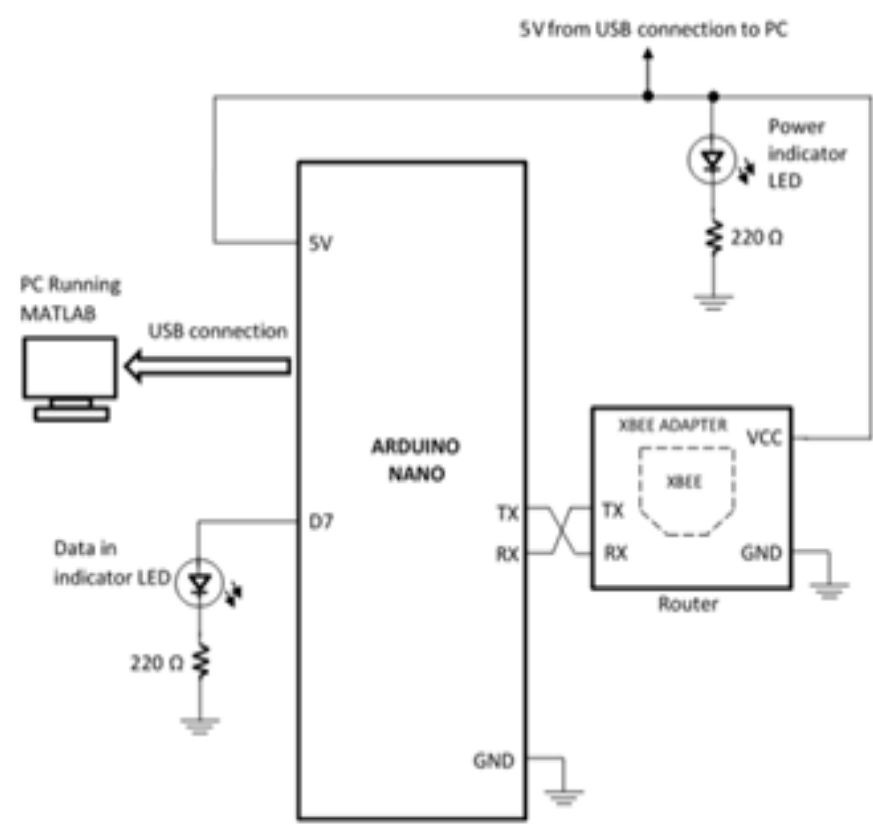

Figure 13: Circuit diagram of receiver section

\section{RESULTS AND DISCUSSION}

The results of the experiment are ion two forms the simulation result and the hardware result shown below.

\subsection{Simulation Result}

The following result, which signifies success in simulation of wireless communication, success in simulation of environmental parameters like temperature, humidity, atmospheric pressure and wind speed and success in simulation of real time graph rendering are displayed in figure 14 below, The graph data streams from proteus to MATLAB in real time and MATLAB plots the graph on a dash board in the GUI also shown in figure 15.

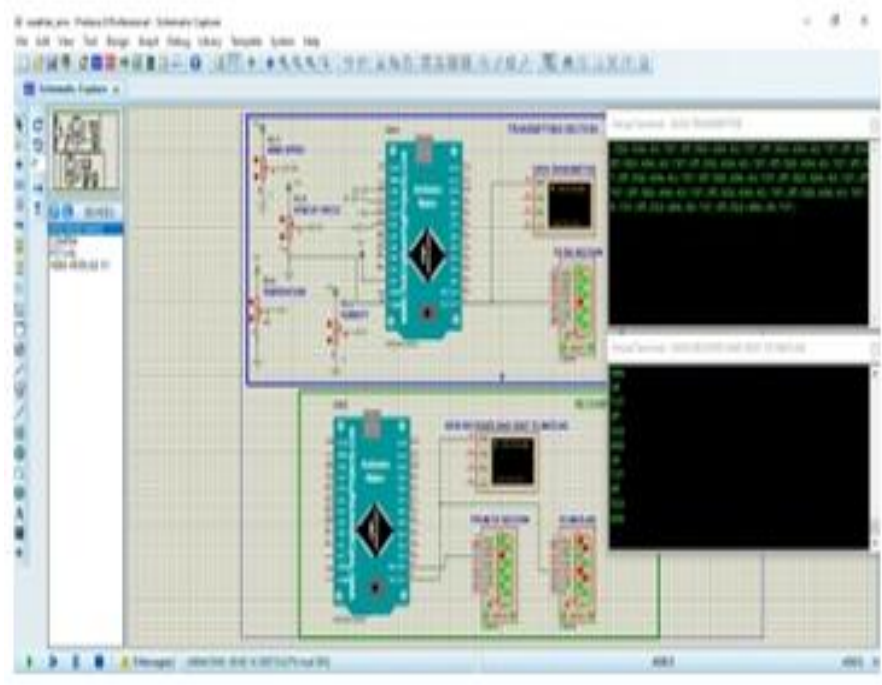

Figure 14: Simulation result from wireless Communication 

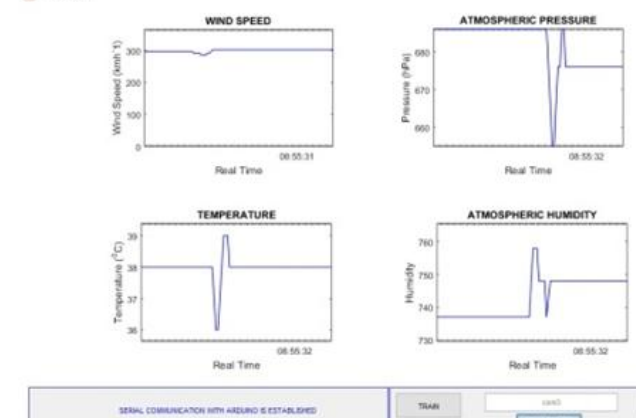

sear The

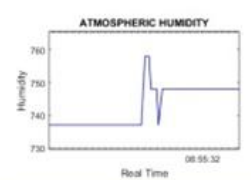

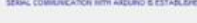

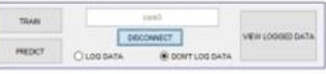

Figure 15: Simulation result showing real time data graphing

\subsection{Implementation Results}

Result after opening MATLAB m-file containing codes for creating GUI is shown in figure 16, while the result of the real time graphing of data from sensor is shown in figure 17.

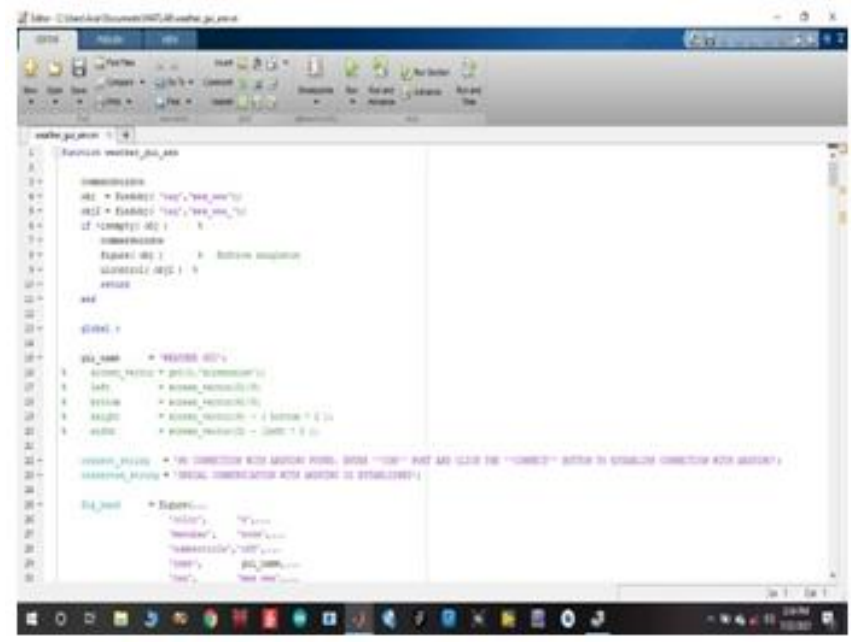

Figure 16: Result after opening MATLAB m-file containing codes for creating GUI

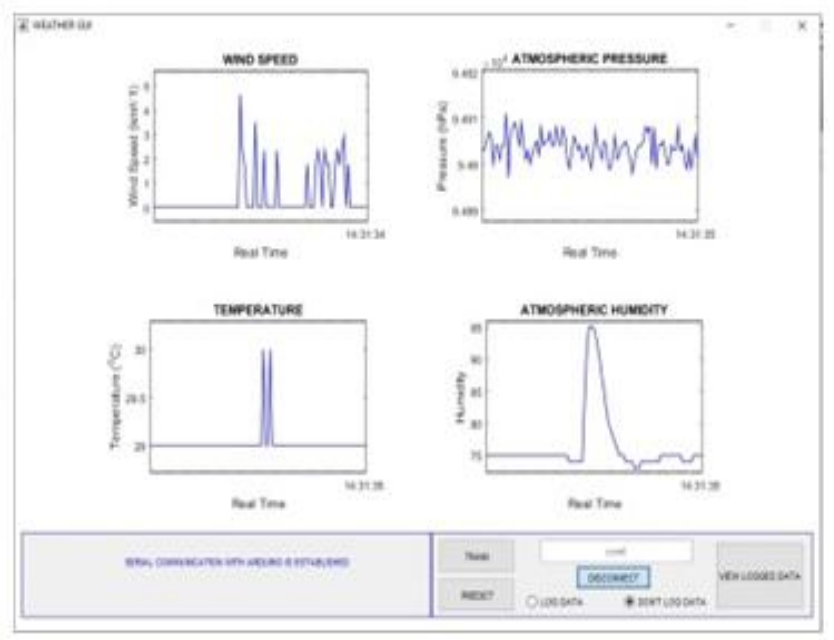

Figure 17: Real time graphing of data from sensor

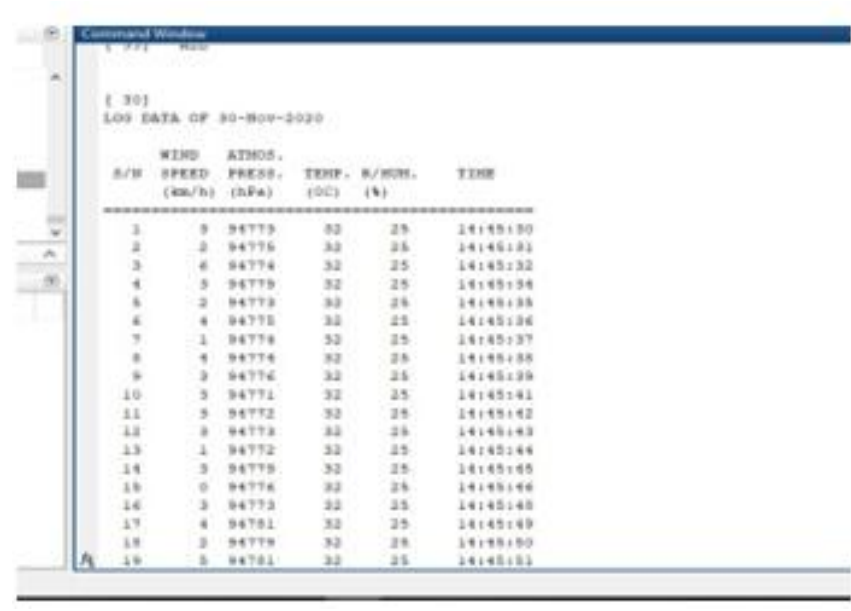

Figure 18: Logged data

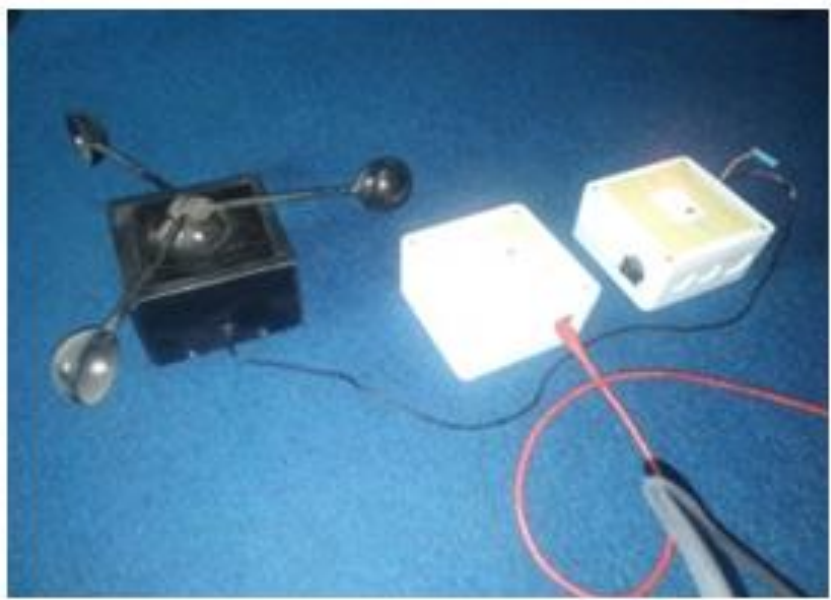

Plate 1: Complete system set up

\section{CONCLUSION}

This project successfully designed, simulated and implemented a wireless sensor network with data logging capabilities. After the design and simulation, the performance of the system was evaluated; a GUI was also successfully developed with dashboard for real time plotting of graph whose data were obtained from the sensors.

\section{FUTURE SCOPE}

Also, further research can be carried out to improve on this work. It could include improving the range of the sensors, so that the system could be installed on remote locations

\section{ACKNOWLEDGEMENT}

This research was funded by the Tertiary Education Trust Fund (TETFUND) under the institutional based-research Federal Polytechnic Mubi. The anonymous reviewers are thanked for their positive comment. 
ISSN (online): 2581-3048

Volume 5, Issue 9, pp 14-20, September-2021 https://doi.org/10.47001/IRJIET/2021.509003

\section{REFERENCES}

[1] M. S. Ismail, "PC-Based Center for Weather Stations in Sudan," Int. J. Recent trends Eng. Res. Dep. Comput. Eng. Fac. Eng., vol. 2, no. 0X, pp. 299-303, 2016.

[2] W. Dargie and C. Poellabauer, Fundamentals of Wireless Sensor Networks: Theory and Practice, First Edit. Southern Gate, Chichester, West Sussex, United Kingdom: John Wiley \& Sons, Ltd, 2010.

[3] F. Rodríguez, A. Fleetwood, A. Galarza, and L. Fontan, "Predicting solar energy generation through artificial neural networks using weather forecasts for microgrid control," Renew. Energy, vol. 126, no. 2018, pp. 855864, 2018.

[4] M. S. Ismail, "PC-Based Center for Weather Stations in Sudan,” Int. J. Recent trends Eng. Res. Dep. Comput. Eng. Fac. Eng., vol. 2, no. 0X, pp. 299-303, 2016.

[5] K. Abhishek, A. Kumar, R. Ranjan, and S. Kumar, "A Rainfall Prediction Model using Artificial Neural Network," in IEEE Control and System Graduate Research Colloquium (ICSGRC 2012), 2012, pp. 8287.

[6] H. Bassil, H. Moubarak, A. Kassem, M. Hamad, and C. El-Moucary, "A Smart Real Time Portable Multichannel Data Logger System," in 29th IEEE International Conference on Microelectronics (ICM), 2017, pp. 512-516.

[7] K. Krishnamurthi, S. Thapa, L. Kothari, and A. Prakash, "Arduino Based Weather Monitoring
System,” Int. J. Eng. Res. Gen. Sci., vol. 3, no. 2, pp. 452-458, 2015.

[8] A.Carre and T. Williamson, "Design and validation of a low cost indoor environment quality datalogger," Energy Build., vol. 158, no. 2018, pp. 1751-1761, 2017.

[9] N. Liu and Z. Su, "Research and Implementation of New Type Multi-channel Data Logger," in 2010 IEEE International Conference on Computer Application and System Modeling (ICCASM 2010), 2010, pp. 102-10.

\section{AUTHORS BIOGRAPHY}

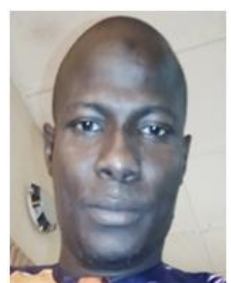

Suleiman Audu. Tarfa

Country: Nigeria

State: Adamawa

City: Yola

Birthday: 03/11/1984

Occupation: Lecturer

Specialization: Telecommunication and Electronics

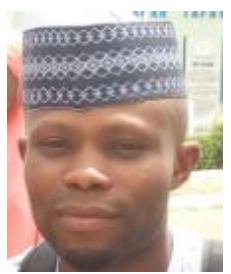

\author{
Chukwuemeka Chijioke Nwaobasi \\ Country: Nigeria \\ State: Imo \\ City: Owerri \\ Birthday: 22/04/1986 \\ Occupation: Lecturer \\ Specialization: Electrical \& Electronics
}

\section{Citation of this Article:}

Suleiman Audu Tarfa, Chukwuemeka Chijioke Nwaobasi, "Wireless Sensor Network Based Weather Forecasting" Published in International Research Journal of Innovations in Engineering and Technology - IRJIET, Volume 5, Issue 9, pp 14-20, September 2021. Article DOI https://doi.org/10.47001/IRJIET/2021.509003 